\title{
OPTIMASI PRODUKSI TAHU DENGAN MENGGUNAKAN METODE PROGRAM DINAMIK
}

\author{
Neneng Herawati*1, Aden ${ }^{2}$, Irvana Arofah $^{3}$, Besse Arnawisuda Ningsi ${ }^{4}$ \\ ${ }^{1}$ Universitas Pamulang, ${ }^{2}$ Universitas Pamulang, ${ }^{3}$ Universitass Pamulang, ${ }^{4}$ Universitas Pamulang \\ nenengherawati090597@gmail.com*1,dosen00527@unpam.ac.id ${ }^{2}$, dosen00351@unpam.ac.id ${ }^{3}$, \\ dosen00205@unpam.ac.id ${ }^{4}$
}

\begin{abstract}
The economy in Indonesia is currently experiencing a very great recession due to the impact of the Covid19 pandemic, this can be seen from economic growth that slows down to below 5\% at the end of 2020. Business competition is getting tighter, as well as "Know" companies must experience intense competition. very tight. The company must be able to meet the incoming demand, and on the other hand the company must be able to reduce the overall production cost to reduce the selling and purchase cost of Tofu in order to get optimal profit. This study aims to determine how to optimize the production of tofu using a recursive dynamic program method. Linear regression is used to predict the amount of production that must be produced in the coming period, then to calculate the minimum production costs and profits according to the scheduling results, the dynamic programming method is used. From the forecast results in the Tofu production data for January-December 2020, the model for the coming period is as follows: $Y^{`}=1925+39 X$. So that the Tofu production schedule for the next 12 periods from January to December 2020 is (2457, 2496, 2536, 2575, 2615, 2654, 2693, 2733, 2772, 2812, 2851, $2890 \mathrm{Kg}$ ). In order to minimize production costs, a dynamic programming method with the objective function is used, in order to obtain a minimum total cost of Rp. 20,292,100, -.
\end{abstract}

Keywords: Linear Regression, Dynamic Program.

\begin{abstract}
Abstrak
Perekonomian di Indonesia sekarang ini mengalami resesi yang sangat hebat karena dampak pandemic Covid-19, hal ini terlihat dari pertumbuhan ekonomi yang melambat hingga di bawah 5\% pada akhir tahun 2020. Persaingan bisnispun semakin ketat, demikian pula perusahaan "Tahu" harus mengalami persaingan yang sangat ketat. Perusahaan harus dapat memenuhi permintaan yang datang, dan disisi lain perusahaan harus dapat menekan biaya produksi keseluruhan untuk menekan biaya jual beli Tahu agar mendapat keuntungan yang optimal. Penelitian ini bertujuan untuk mengetahui bagaimana optimalisasi produksi tahu dengan menggunakan metode program dinamik rekursif. Untuk meramal jumlah produksi yang harus diproduksi pada periode mendatang digunakan regresi linier, kemudian untuk menghitung biaya produksi minimum dan keuntungan sesuai dengan hasil penjadwalan digunakan metode program dinamik. Dari hasil ramalan pada data produksi Tahu Januari-Desember 2020 didapat model untuk periode mendatang adalah sebagai berikut : $Y^{`}=1925+39$ X. Sehingga jadwal produksi Tahu untuk 12 periode mendatang Januari-Desember 2020 adalah $(2457,2496,2536,2575,2615,2654,2693,2733,2772,2812,2851,2890$ $\mathrm{Kg}$ ). Untuk meminimumkan biaya produksi maka digunakan metode program dinamik dengan fungsi tujuan, sehingga didapat total biaya minimum sebesar Rp. 20.292.100,--
\end{abstract}

Kata kunci: Regresi Linier, Program Dinamik. 


\section{PENDAHULUAN}

Sekarang ini perekonomian di Indonesia mengalami resesi yang sangat hebat karena dampak pandemic Covid-19, hal ini terlihat dari pertumbuhan ekonomi yang melambat hingga di bawah 5\% pada akhir tahun 2020. Persaingan bisnispun semakin ketat, sehingga suatu perusahaan harus mampu bersaing dan memberikan pelayanan yang baik dan memuaskan untuk pelanggannya. Hal ini menyebabkan perindustrian dapat tumbuh di Indonesia secara langsung. Selain itu perusahaan perlu merencanakan operasional produksi dengan baik agar meminimalisis biaya-biaya yang diperlukan saat kegiatan produksi.

Perusahaan yang bergerak di bidang yang sama perlu berusaha semaksimal mungkin untuk meningkatkan kualitas produk pelayanan agar dapat bertahan dan bersaing didalam perusahaan industri. Untuk itu, industri-industri diharapkan mampu memahami sistem perencanaan produksi yang baik. Karena perencanaan produksi pada dasarnya adalah usaha perusahaan untuk mengatasi fluktuasi (permintaan). Dan diharapkan pihak perusahaan mampu untuk terus meningkatkan efisiensi serta kemampuan untuk menghasilkan produk yang bermutu guna memenuhi pasar dan konsumen.

Tahu adalah salah satu usaha industri yang mampu bersaing sampai saat ini. Makanan hasil variasi olahan kacang kedelai ini pun makanan yang populer karena harganya yang relatif terjangkau untuk dikonsumsi masyarakat dari berbagai lapisan. Hal yang menarik dari beberapa industri tahu adalah skala industrinya yang kebanyakan masih berupa industri kecil dan menengah yang perproduksi dengan metode tradisional, padahal daya beli masyarakat untuk produk ini relatif tinggi. Meskipun didalam persaingan dengan makanan luar negeri, tahu tetep eksis di pasaran. Pasar untuk produk ini pun tergolong cukup luas, namun biasanya konsumen tahu merupakan kalangan menengah kebawah.

Usaha Industri tahu merupakan salah satu usaha dagang yang bergerak dalam produk tahu. Salah satunya industri tahu di daerah Sukawati yang lumayan berkembang adalah Usaha Industri Pabrik "Tahu” Bapak Tohir, yang di dirikan pada Tahun 2000 ini memiliki berbagai macam produksi tahu. Perusahaan tahu menerapkan sistem make to stok guna dapat dengan cepat merespon permintaan konsumen sehingga konsumen ataupun pelanggan tidak perlu menunggu waktu yang lama untuk mendapatkan produknya. Masalah yang dihadapi perusahaan adalah permintaan produk mengalami naik turun pada setiap periode. Hal ini disebabkan karena permintaan konsumen terhadap produk yang selalu berubah dipasar luas, masalah yang disebabkan naik turunnya permintaan produk membuat perusahaan sering 
mengalami suatu masalah yang berkaitan dengan berapa banyak produk yang harus diproduksi pada setiap waktunya/periode.

Hal ini menyebabkan pada setiap periode, perusahan industri ini sering mengalami kelebihan atau kekurangan produk sehingga mengakibatkan biaya produksi yang dikeluarkan perusahaan belum efisien. Sehingga perolehan keuntungan yang didapat oleh perusahaan tidak optimal.

Berdasarkan hal tersebut maka diperlukan suatu metode untuk menyusun jadwal produksi secara baik dan terencana sehingga dapat dijadikan sebagai pedoman oleh perusahaan untuk memproduksi suatu produk agar memenuhi permintaan konsumen dan biaya yang dikeluarkan dapat minimum. Untuk itu, penulis ingin menyelesaikan masalah pengendalian persediaan dengan menggunakan program dinamik rekursif maju.

Program dinamik merupakan salah satu teknik matematika yang digunakan untuk mengoptimalkan proses pengambilan keputusan secara bertahap ganda. Salah satu Inti dari teknik ini adalah membagi satu persoalan terhadap beberapa bagian persoalan (tahap), kemudian memecahkan tiap tahap sampai seluruh persoalan telah terpecahkan. Proses pemecahan masalah dalam program dinamik dilakukan secara rekursif. Artinya, setiap kali diambil keputusan, diperhatikan kondisi yang dihasilkan oleh keputusan sebelumnya.

\section{METODE PENELITIAN}

Jenis penelitian yang digunakan pada penelitian ini adalah jenis penelitian terapan. Terapan yang dimaksud disini adalah bertujuan untuk menemukan solusi atas suatu masalahmasalah praktis yang secara langsung dihadapi oleh masyarakat, atau organisasi industri/bisnis. (Sugiono, 2019). Menggunakan metode yang telah ada kemudian akan diterapkan atau diaplikasikan pada penelitian ini.

Metode pengumpulan data pada penelitian ini adalah dengan menggunakan sebagian data yang dimiliki oleh perusahan tahu, dan ada juga yang dilakukan dengan cara wawacara dan observasi.

Data-data yang digunakan dalam penelitian ini adalah data permintaan pada periode 2019 . Data lain yang di ambil adalah biaya-biaya produksi pada tahun 2019.

Analisis data menggunakan tekhnik analisis data deskriptif kuantitatif dengan tahapantahapan sebagai berikut: (1) menghitung regresi linier. (2) dilakukan perhitungan menggunakan metode program dinamik, untuk mendapatkan keputusan yang optimal.

\section{Persamaan Regresi Linier}


Model Regresi Linier Sederhana yaitu regresi linier dengan satu variabel prediktor (bebas) dapat ditulis sebagai berikut :

$$
\hat{Y}=a+b X
$$

Untuk mencari nilai a dan b pada persamaan regresi dapat dihitung dengan rumus di bawah ini:

$$
\begin{aligned}
& b=\frac{n \sum X Y-\sum X \cdot \sum Y}{n \sum X^{2}-\left(\sum X\right)^{2}} \\
& a=\frac{\sum Y \sum X^{2}-\sum X \cdot \sum X Y}{n \sum X^{2}-\left(\sum X\right)^{2}}
\end{aligned}
$$

\section{Pengendalian Persediaan}

Manajemen pengendalian persediaan atau pengendalian persediaan inventory control yaitu pengendalian persediaan dapat dikatakan sebagai suatu kegiatan untuk menentukan tingkat dan komposisi dari persediaan suku cadang, bahan baku, dan barang hasil produksi. Untuk itu, perusahaan dapat melindungi kelancaran produksi dan penjualan serta kebutuhan- kebutuhan pembelanjaan dengan efektif dan efisien.

\section{Program Dinamik}

Program dinamik merupakan salah satu teknik matematika yang digunakan untuk mengoptimalkan proses pengambilan keputusan secara bertahap ganda. Suatu sub masalah yang berurutan dan saling berhubungan. Dalam matematika, definisi rekursif sebuah fungsi atau definisi fungsi yang menggunakan fungsi tersebut. Ada dua macam prosedur rekursif yaitu forward recursive equation (perhitungan dari depan kebelakang) dan backward recursive equation (perhitungan dari belakang kedepan).

4. forward recursive equation dan backward recursive equation

Penyelesaian program dinamik dilakukan dengan perhitungan rekursif yang berulang setiap tahap. Keputusan optimum pada suatu tahap adalah hasil optimum pada tahap tersebut ditambah hasil optimum tahap sebelumnya.

$$
f_{n}\left(I_{n}\right)=\operatorname{Min}\left\{\left(A X_{n}+Y\left(I_{n}\right)+f_{n-1}\left(I_{n-1}\right)\right)\right\} \quad n=1,2,3, \ldots . .12
$$

Persamaan rekursif di atas dapat ditulis, sebagai berikut :

$$
\text { Rekursif Maju : } f_{n}\left(I_{n}\right)=\operatorname{Min}\left\{\left(A X_{n}+B\left(I_{n}\right)\right)+f_{n-1}\left(I_{n}+S_{n}-X_{n}\right)\right\}
$$


Rekursif Mundur: $f_{n}\left(I_{n}\right)=\operatorname{Min}\left\{\left(A X_{n}+B\left(I_{n}\right)\right)+f_{n+1}\left(I_{n}+S_{n}-X_{n}\right)\right\}$

\section{Formulasi dengan Perogram Dinamik}

Urutan perencanaan produksi dengan program dinamik ditunjukkan pada tahapan berikut :

1) Dekomposisi, permasalahan rencana produksi dipecah menjadi beberapa submasalah dalam penelitian ini dinyatakan dengan tahap 1 sampai tahap 12 .

2) Menentukan variabel masukan atau state pada tiap tahapan, dalam hal ini adalah hasil peramalan, kapasitas tersedia, biaya variabel produk, dan biaya simpan.

3) Menentukan variabel keputusan, dalam penelitian ini adalah menentukan jumlah produksi berdasarkan persediaan.

4) Menetapkan fungsi tujuan :

$\operatorname{Min} C=\sum_{n-1}^{12}(A X n-B I n)$

5) Dengan batasan jumlah produksi yang dilakukan tidak melebihi kapasitas produksi yang tersedia. Formulasi matematisnya, yaitu :

$I_{n}+S_{n}-G \leq I_{n}+S_{n}$

6) Menetapkan persamaan rekursif

Penyelesaian program dinamik dilakukan dengan perhitungan rekursif yang berulang setiap tahap. Keputusan optimum pada suatu tahap adalah hasil optimum pada tahap tersebut ditambah hasil optimum tahap sebelumnya.

$f_{n}\left(I_{n}\right)=\operatorname{Min}\left\{\left(A X_{n}+Y\left(I_{n}\right)+f_{n-1}\left(I_{n-1}\right)\right)\right\} \quad n=1,2,3, \ldots . .12$

Persamaan rekursif di atas dapat ditulis, sebagai berikut :

Rekursif Maju : $f_{n}\left(I_{n}\right)=\operatorname{Min}\left\{\left(A X_{n}+B\left(I_{n}\right)\right)+f_{n-1}\left(I_{n}+S_{n}-X_{n}\right)\right\}$

Rekursif Mundur : $f_{n}\left(I_{n}\right)=\operatorname{Min}\left\{\left(A X_{n}+B\left(I_{n}\right)\right)+f_{n+1}\left(I_{n}+S_{n}-X_{n}\right)\right\}$

$f_{n}\left(I_{n}\right)$ : biaya produksi minimum tahu pada tahap $n$ dalam banyak persediaan $S$.

$A X_{n} \quad$ : Biaya produksi tahu dalam tahap $n$.

$B\left(I_{n}\right)$ : Biaya perawatan yang dikenakan terhadap tahap $n$ apabila dalam banyaknya persediaan.

$s_{n} \quad$ : Banyaknya permintaan atau penjualan dalam tahap $n$. 


\section{HASIL DAN PEMBAHASAN}

Sehingga persamaan regresi dalam kasus ini adalah $\hat{Y}=1925+39$ X Dimana Y adalah ramalan permintaan dan X adalah periode. Koefisien regresi X sebesar 39 mempunyai arti bahwa setiap penambahan 1 periode maka ada penambahan jumlah permintaan Tahu sebesar $39 \mathrm{~kg}$.

Tabel 1. Hasil Peramalan Periode Januari-Desember 2020.

\begin{tabular}{|c|l|c|}
\hline NO & \multicolumn{1}{|c|}{ Periode } & Ramalan Permintaan $(\mathrm{kg})$ \\
\hline 1 & Januari & 2433 \\
\hline 2 & Februari & 2472 \\
\hline 3 & Maret & 2511 \\
\hline 4 & April & 2550 \\
\hline 5 & Mei & 2589 \\
\hline 6 & Juni & 2628 \\
\hline 7 & Juli & 2667 \\
\hline 8 & Agustus & 2706 \\
\hline 9 & September & 2745 \\
\hline 10 & Oktober & 2784 \\
\hline 11 & November & 2823 \\
\hline 12 & Desember & 2862 \\
\hline
\end{tabular}

Tabel 2. Hasil Penyesuaian Terhadap Prosentase Cacat Produk Periode JanuariDesember 2020.

\begin{tabular}{|l|l|c|}
\hline NO & Periode & $\begin{array}{c}\text { Jumlah yang harus } \\
\text { di produksi }(\mathrm{Kg})\end{array}$ \\
\hline 1 & Januari & 2457 \\
\hline 2 & Februari & 2496 \\
\hline 3 & Maret & 2536 \\
\hline 4 & April & 2575 \\
\hline 5 & Mei & 2615 \\
\hline 6 & Juni & 2654 \\
\hline 7 & Juli & 2693 \\
\hline
\end{tabular}




\begin{tabular}{|l|l|c|}
\hline NO & Periode & $\begin{array}{c}\text { Jumlah yang harus } \\
\text { di produksi }(\mathrm{Kg})\end{array}$ \\
\hline 8 & Agustus & 2733 \\
\hline 9 & September & 2772 \\
\hline 10 & Oktober & 2812 \\
\hline 11 & November & 2851 \\
\hline 12 & Desember & 2890 \\
\hline
\end{tabular}

Selanjutnya untuk mengukur ketepatan peramalan maka digunakan nilai tengah kesalahan absolut (MAD):

$$
M A D=\frac{3755}{12}=312,9
$$

Selanjutnya hasil peramalan digunakan untuk melakukan perencanaan produksi selama 12 periode kedepan dengan menggunakan program dinamik. Perhitungan dengan metode program dinamik menggunakan fungsi rekursif dengan biaya variabel produk per kemasan sebesar Rp. 15.000 dan biaya simpan produk per kemasan sebesar Rp. 5.000 dimana setiap tahap saling berhubungan dan perhitungan dimulai dari tahap 1 sampai dengan tahap 12 dengan ketentuan sebagai berikut:

$$
\begin{aligned}
& f_{n}\left(I_{n}\right)=\min \left\{\left((15000) X_{n}+(5000) I_{n}\right)+f_{n-1}\left(I_{n}+S_{n}-X_{n}\right)\right\} \\
& I_{n}+S_{n}-100 \leq X_{n} \leq I_{n}+S_{n} \\
& I_{n} \leq 100, n=1,2,3 \ldots 12
\end{aligned}
$$

\section{Penyelesaian Dengan Program Dinamik Rekursif Maju}

Langkah terakhir yang dilakukan adalah melakukan penyusunan perencanaan jadwal produksi dengan biaya minimum menggunakan metode program dinamik untuk jangka waktu perencanaan satu tahun dengan periode satu bulan, sehingga terdapat 12 tahap pelaksanaan yang dimulai pada bulan januari-desember 2020. Solusi optimal akan diperoleh berdasarkan jumlah total biaya produksi minimum yang diperoleh dari masing-masing alternatif kebijakan produksi yang disusun sebagai berikut:

$\underline{\text { Tahap } 1}$

$$
\begin{gathered}
f_{1}\left(I_{1}\right)=\operatorname{Min}\left\{\left(A . X_{1}+B . I_{1}\right)\right\} \\
I_{1}+S_{1}-I_{0} \leq X_{1} \leq I_{0}+S_{0} \\
2457 \leq X_{1}
\end{gathered}
$$


Diketahui $\mathrm{S}_{1}=2457$ (jumlah penjualan dalam periode pertama dan $0 \leq I_{1} \leq 100$ ), dan hal ini didapatkan hasil sebagai berikut :

$$
\begin{aligned}
& f_{1}(0)=(100.2457+5000.0)=245700 \\
& f_{1}(60)=(100.2510+5000.60)=551000 \\
& f_{1}(80)=(100.2590+5000.80)=659000 \\
& f_{1}(90)=(100.2680+5000.90)=718000 \\
& f_{1}(100)=(100.2780+5000.100)=778000
\end{aligned}
$$

Dapat dilihat bahwa dari 5 variasi persediaan terdapat satu alternatif yang menghasilkan biaya minimum. Sehingga kebijakan yang dipilih adalah kebijakan yang menghasilkan biaya produksi minimum . dalam tahap ini biaya produksi minimum terdapat pada tahap $I_{1}=0$ dengan biaya Rp. 245.700,--

\section{Tahap 2}

Untuk tahap ini perhitungannya tidak hanya tahap 2 itu saja, tetapi juga memperhitungkan biaya produksi pada tahap sebelumnya (tahap 1) sesuai dengan alternatif kebijakan produksi yang dipilih dengan jumlah persediaan tahu 0,60,80,90 dan $100 \mathrm{Kg}$. Pada tahap ini terdapat 25 alternatif kebijakan produksi.

$$
\begin{gathered}
f_{2}(0)=\min \left\{\left(A . X_{2}+B . I_{2}\right)+f_{1}\left(I_{2}+S_{2}-X_{2}\right)\right\} \\
I_{2}+S_{2}-100 \leq X_{2} \leq I_{2}+S_{2} \\
2396 \leq X_{2} \leq 2496
\end{gathered} \quad\left\{\begin{array}{l}
(100.2396+5000.0)+f_{1}(0+2496-2396)=1017600 \\
(100.2406+5000.0)+f_{1}(0+2496-2406)=958600 \\
f_{2}(0)=\min \left\{\begin{array}{l}
100.2416+5000.0)+f_{1}(0+2496-2416)=900600 \\
(100.2436+5000.0)+f_{1}(0+2496-2436)=794600 \\
(100.2496+5000.0)+f_{1}(0+2496-2496)=495300
\end{array}\right.
\end{array}\right.
$$

Dapat diketahui bahwa total biaya yang minimum diperoleh pada produksi dengan jumlah persediaan $I_{2}=0$.

Perhitungan tersebut berulang sampai tahap ke-12 yaitu Desember 2020. Pada lampiran dua dapat diketahui bahwa setiap tahap terdapat 25 alternatif kebijakan produksi, kecuali pada tahap pertama yang mempunyai 5 alternatif kebijakan produksi.

Tabel 3. Hasil Penjadwalan Produksi Tahu Periode Januari-Desember 2020. 
Jurnal Lebesgue : Jurnal Ilmiah Pendidikan Matematika, Matematika dan Statistika

Neneng Herawati, Aden, Irvana Arofah, Besse Arnawisuda Ningsi

Volume 2, No. 1, April 2021 hal.34-44

DOI Artikel : 10.46306/lb.v2i1.54

\begin{tabular}{|l|c|c|c|c|}
\hline Periode & $\begin{array}{l}\text { Permintaan } \\
(\mathrm{Kg})\end{array}$ & $\begin{array}{l}\text { Produksi } \\
(\mathrm{Kg})\end{array}$ & $\begin{array}{l}\text { Persediaan } \\
(\mathrm{Kg})\end{array}$ & $\begin{array}{l}\text { Biaya Minimum } \\
(\mathrm{Rp})\end{array}$ \\
\hline Januari & 2457 & 2457 & 0 & 245700 \\
\hline Februari & 2496 & 2496 & 0 & 495300 \\
\hline Maret & 2536 & 2536 & 0 & 748900 \\
\hline April & 2575 & 2575 & 0 & 1006500 \\
\hline Mei & 2615 & 2615 & 0 & 1268000 \\
\hline Juni & 2654 & 2654 & 0 & 1533400 \\
\hline Juli & 2693 & 2693 & 0 & 1802700 \\
\hline Agustus & 2733 & 2733 & 0 & 2076000 \\
\hline September & 2772 & 2772 & 0 & 2353200 \\
\hline Oktober & 2812 & 2812 & 0 & 2634400 \\
\hline November & 2851 & 2851 & 0 & 2919500 \\
\hline Desember & 2890 & 2890 & 0 & 3208500 \\
\hline Total & 32084 & 32084 & 0 & 20292100 \\
\hline & & & & 0 \\
\hline
\end{tabular}

Berdasarkan tabel 3 di atas dapat diketahui bahwa jumlah produksi tahu untuk januaridesember 2020 selalu sama dengan jumlah permintaan konsumen sehingga pada setiap tahapnya tidak memiliki persediaan gudang. Berdasarkan hasil tersebut, biaya total minimum selalu diperoleh pada angka persediaan $I_{n}=0$. Hal ini dapat terjadi karena dengan semakin sedikit persediaan atau bahkan tidak adanya persediaan akan mengurangi jumlah biaya total karena kecilnya biaya simpan bila dibandingkan dengan biaya produksi. Biaya yang dikeluarkan untuk jadwal produksi selama periode 2020 tersebut adalah Rp. 20.292,100,-. Ini merupakan hasil optimal dalam meminimumkan biaya produksi dengan menggunak metode program dinamik.

\section{KESIMPULAN}

Berdasarkan hasil penelitian yang dilakukan kepada perusahaan "Tahu Bapak Tohir" Sukawati, langkah pertama yang dilakukan adalah menggunakan metode regresi linier dalam 
meramalkan permintaan untuk 12 periode mendatang mendatang (januari-desember 2020) adalah 2457, 2496, 2536, 2575, 2615, 2654, 2693, 2733, 2772, 2812, 2851, $2890 \mathrm{Kg}$. Adapun jumlah produksi untuk 12 periode mendatang ( januari-desember 2020) adalah 2457, 2496, 2536, 2575, 2615, 2654, 2693, 2733, 2772, 2812, 2851, $2890 \mathrm{Kg}$, langkah selanjutnya digunakan metode program dinamik untuk memperoleh total biaya minimum untuk 12 periode sebesar Rp. 20.292.100,-.Adapun keuntungan yang didapat sebelum menggunakan program dinamik sebesar Rp.118.263.600.- sedangkan keuntungan yang didapat setelah menggunakan metode program dinamik adalah sebesar Rp. 121.919.200.-

Perencanaan penjadwalan produksi menggunakan metode Program Dinamik memberikan hasil yang lebih optimal dari segi keuntungan apabila dibandingkan keuntungan yang diperoleh tanpa menggunakan metode Program Dinamik.

\section{DAFTAR PUSTAKA}

Agustina Eunik, Nasir Widha Setyanto, Rahmi Yuniarti, Ihwan Hamdala, Rio Prasetyo Lukodona, A. A. F. (2018). Perencanaan Produksi dan Pengendalian Persediaan. UB Press. http://www.ubpress.ub.ac.id

Andi Rianata Brahmana, Poerwanto, T. S. S. (2013). Optimasi Produksi Dengan Program Dinamis Pada Pabrik Fractination and Refinery Factory (Frf) Pt. Xyz. Jurnal Teknik Industri USU, 3(4), 49-54.

Bambang Herry Purnomo, Yuli Wibowo, K. M. (2015). Perencanaan Produksi Kerupuk Puli Dengan Metode Program Dinamik Di UD RIZKY JEMBER. 9(1), 63-70. https://doi.org/https://doi.org/10.21107/agrointek.v9i1.2125

Dardiri, Y. H., \& Arhasy, E. A. (2020). MEDIA TAHU KUNING UNTUK MENINGKATKAN AKTIVITAS DAN PRESTASI BELAJAR MATEMATIKA. Jurnal Lebesgue: Jurnal Ilmiah Pendidikan Matematika, Matematika dan Statistika, 1(2), 91-104.

Delfianda, P., Komalig, H., \& Manurung, T. (2015). Optimalisasi Biaya Total Perencanaan dan Pengendalian Persediaan Menggunakan Program Dinamik (Studi Kasus: Nabila Bakery SPMA Kalasey Manado). D'CARTESIAN, 4(1), 8. https://doi.org/10.35799/dc.4.1.2015.6816

Dr. Ir. Prasadja Ricardianto, M. (2019). Managemen Oprasi Bidang Transportasi dan Logistik. In Media.

Dr. Supardi U.S., MM., M. P. (2013). Aplikasi Statistik Dalam Penelitian. In Aplikasi Statistik Dalam Penelitian. CHANGE PUBLICATION.

Hilma Nuf'a, Lily Montarcih Limantara, W. S. (2016). Optimasi Air Waduk Gondang Dengan Metode Dinamik Deterministik. 7(1), 25-34.

Maslihah, S. (2018). Program Dinamik Untuk Pendistribusian Komoditi Kerupuk '9 Berlian' Wates. At-Taqaddum, 10(1Maslihah, S. (2018). Program Dinamik Untuk Pendistribusian Komoditi Kerupuk '9 Berlian' Wates. At-Taqaddum, 10(1), 81. https://doi.org/10.21580/at.v10i1.2541), 81. https://doi.org/10.21580/at.v10i1.2541

Nurhidayati, F. U. (2010). Penggunaan Program Dinamik untuk Menentukan Total Biaya Minimum pada Perencanaan Produksi dan Pengendalian Persediaan. Etheses Uin Malang,37-61 
Volume 2, No. 1, April 2021 hal.34-44

DOI Artikel : 10.46306/lb.v2i1.54

Rachma, E. A. (2020). Optimasi Perencanaan Produksi Dengan Menggunakan Model Sistem Dinamik Di PT X. Jurnal Optimasi Teknik Industri (JOTI), 02(01), 36-42. https://doi.org/http://dx.doi.org/10.30998/joti.v2i1.4425

Zulhelmi, dkk. 2017. Pengaruh Media Pembelajaran Interaktif Terhadap Peningkatan Keterampilan Berpikir Kritis Siswa: Jurnal Pendidikan Sains Indonesia: Vol. 05, No. 01, hlm 73-80 